\title{
JUDICIALIZAÇÃO DA SAÚDE: PERSPECTIVAS DE UMA CONFORMAÇÃO DE EFETIVIDADE
}

\author{
JUDICIALIZATION OF HEALTH: A PERSPECTIVE OF EFFECTIVENESS
}

\author{
${ }^{1}$ Claudia Mota Estabel \\ ${ }^{2}$ Andreia Castro Dias
}

\section{RESUMO}

O presente trabalho tem como escopo sintetizar a judicialização do direito à saúde, e oferecer uma perspectiva para conformação de efetividade. Utilizando-se o método indutivo e tendo por base pesquisa bibliográfica e jurisprudencial, no primeiro momento será apresentado um breve histórico do direito à saúde, bem como alguns dos princípios relativos a este preceito fundamental. Por segundo, a partir de uma abordagem normativa e jurisprudencial, será apresentado o direito à saúde na perspectiva do Poder Judiciário, como foco nos instrumentos já utilizados (decisões judiciais), do número de demandas existentes que dizem respeito ao tema da saúde, e das políticas públicas adotadas pelo judiciário tanto em sua própria esfera quanto administrativamente. Por fim, enfatizar-se-á as questões diversas no processo judiciário da saúde, no tocante à responsabilidade solidária dos entes federativos e as diretrizes para uma adequada conformação do direito à saúde, ao efeito de promover a cidadania e a justiça social.

Palavras-chave: Saúde, Judicialização, Cidadania, Justiça social

\begin{abstract}
This work is scoped to synthesize the legalization of the right to health, and offer a perspective for shaping effectiveness. Using the inductive method and based on research literature and case law, at first a brief history of the right to health will be presented as well as some of the principles relating to fundamental precept. Per second, from a normative and jurisprudential approach, the right will be presented to health in the judiciary perspective, focused on the instruments already used (court decisions), the number of demands that concern the health issue, and public policies adopted by the judiciary both in its own sphere as administratively. Finally, emphasis shall be the various issues in the legal health procedure regarding the joint responsibility of federal entities and guidelines for proper conformation of the right to health, the effect of promoting citizenship and social justice.
\end{abstract}

Keywords: Health, Judicialization, Citizenship, Social justice

\footnotetext{
${ }^{1}$ Mestranda em Direito e Justiça Social pela Universidade Federal do Rio Grande - FURG, Rio Grande do Sul (Brasil). Professora titular junto a Faculdade Anhanguera (Brasil). E-mail: claudia.estabel@ aedu.com

${ }^{2}$ Mestranda em Direito e Justiça Social pela Universidade Federal do Rio Grande - FURG, Rio Grande do Sul (Brasil). Juíza Federal na $3^{\text {a }}$ Vara Federal da Subseção Judiciária de Rio Grande do Sul, Rio Grande do Sul (Brasil). E-mail: deiacastrodias@hotmail.com
} 


\section{INTRODUÇÃO}

O presente estudo tem por finalidade contextualizar o direito à saúde e as políticas públicas que vem sendo promovidas por intermédio do Poder Judiciário quando instado a se manifestar. A propósito, o direito à saúde vem insculpido na Constituição Federal Brasileira de 1988, inicialmente de maneira implícita no artigo $1^{\circ}$, quando fundamenta o estabelecimento do Estado Brasileiro na promoção da dignidade da pessoa humana. Vem também inscrito na referida carta constitucional como direito fundamental social do indivíduo $\left(\right.$ art. $\left.6^{\circ}\right)$, e, portanto, disso decorre a correlata responsabilidade do Estado para sua efetivação e manutenção.

Entrementes, mesmo sendo direito fundamental social, tem-se verificado a inocorrência de políticas públicas satisfatórias, além de ausência ou limitação econômicofinanceira para sua prestação por parte dos poderes constituídos que deveriam prestá-lo. Ademais, não obstante o Sistema Único de Saúde tenha por supedâneo, para sua efetivação, os princípios da universalidade e igualdade de tratamento aos indivíduos, na prática acaba sendo insuficiente o atendimento diante da elevada demanda existente.

Nesse passo, quando inviabilizada a prestação estatal no tocante à efetivação do direito à saúde pelo Poder Executivo/Legislativo, o cidadão, vendo-se premido em suas necessidades básicas, acaba por socorrer-se do Poder Judiciário, no intuito de ver garantido dito preceito fundamental, fato que impulsiona a judicialização da saúde.

Desta feita, o presente trabalho pretende apresentar a responsabilidade do Estado no tocante à satisfação do direito à saúde quando instado judicialmente para tanto, e neste contexto, indicar conformações para sua efetividade.

Para tanto, será necessário abordar-se sobre o direito à saúde no Brasil, formulando- se um breve histórico em uma perspectiva mundial e nacional, indicando, nessa senda, os princípios constitucionais que mais se destacam na sua conformação. De outro lado, pretendese discorrer sobre a responsabilidade solidária dos entes federativos relativamente à saúde, bem como a possibilidade de intervenção do Poder Judiciário nas demandas que tencionam a proteção à saúde. Ainda no tocante a atuação do Poder Judiciário frente à promoção do direito à saúde, será fundamental a análise do posicionamento dos tribunais superiores frente à matéria, passando-se pela jurisprudência do Supremo Tribunal Federal, o qual apresentou novos contornos às ações sanitárias, ao sopesar a questão orçamentária em matéria de saúde e o direito subjetivo individual à mesma. Nessa ótica, importante será a verificação do crescente número 
de demandas judiciais que buscam dita tutela, o que detém análise específica no presente estudo com base nas informações colhidas junto ao Conselho Nacional de Justiça e nos tribunais regionais federais e estaduais. Por fim, apresentar-se-á diretrizes para uma conformação do direito à saúde, por parte da gestão administrativa do Poder Judiciário, quando se retomará a questão da promoção de políticas públicas tendentes à efetivação da cidadania e da justiça social.

Assim, utilizando-se do método indutivo, o trabalho desenvolve-se por meio de pesquisa bibliográfica, com análise doutrinária, legislativa e jurisprudencial, dividindo-se em três capítulos, quais sejam: Breve histórico do direito à saúde; o Poder Judiciário e o direito à saúde e Questões diversas nos processos judiciais de saúde, o que se faz necessário, porquanto como direito fundamental, a assistência à saúde não recebe da máquina estatal, na prática, a atenção dispensada pelo constituinte brasileiro no texto da Carta de 1988, cabendo aos interessados a procura do Poder Judiciário para solução dos litígios.

\section{DIREITO À SAUDE NO BRASIL}

\subsection{Breve histórico- perspectiva constitucional e legal}

Nos termos percebidos pela Organização Mundial da Saúde (OMS), o conceito de saúde consiste no "completo estado de bem-estar físico, mental e social, e não simplesmente a ausência de enfermidade". Ao enfrentar esta perspectiva, e, levando-se em conta que o direito à saúde não se caracteriza meramente pela ausência de enfermidade, este envolverá a promoção, a proteção e a recuperação da saúde.

No contexto internacional, o direito à saúde foi reconhecido após o fim da Segunda Guerra Mundial, marco para a valorização dos direitos humanos na figura da dignidade da pessoa. Encontra base o direito à saúde em documentos internacionais, como a Declaração Universal dos Direitos do Homem (1948), o Pacto de Direitos Sociais, Econômicos e Culturais (1992), bem assim o Pacto de San Jose da Costa Rica (1992).

A legislação brasileira, por sua vez, em seus primórdios, não se preocupou com a temática, basta ver que nas Constituições Federais de 1824 e 1891 sequer havia menção a referido direito. Note-se que foi apenas na Constituição de 1934 que se abordou pela primeira vez sobre o tema, e, ainda assim, associando-o ao direito do trabalho. Já na Carta Constitucional de 1937, a saúde estava relacionada ao bem estar e desenvolvimento da criança, enquanto 
que a Carta de 1946 trouxe a saúde como competência da União. Durante o período de exceção, entre 1967 e 1969, não houve significativa atenção ao direito relacionado à saúde e somente com a Constituição Federal de 1988, que o direito à saúde atingiu o ápice da proteção já dispensada pelo Estado, identificando-o como direto fundamental social dos indivíduos (artigos 6 $6^{\circ}, 196$ a 200 da Carta). A propósito, dita proteção sofreu forte influência da Conferência Nacional da Saúde de 1986, a qual traçou parâmetros para a proteção e desenvolvimento do direito sanitário.

Em termos de legislação infraconstitucional, o direito à saúde foi consagrado na Lei 8.080/1990 (criando o Sistema Único de Saúde), a qual, em seu artigo $1^{\circ}$, consagrou a sua aplicação às ações e serviços de saúde, executados isolada ou conjuntamente, em caráter permanente ou eventual, por pessoas naturais ou jurídicas de direito Público ou privado. Importante referir que em seu artigo $2^{\circ}$ ratifica a escolha do Poder Constituinte Originário, ao afirmá-lo como direito fundamental do ser humano, devendo o Estado prover as condições indispensáveis ao seu pleno exercício. Ademais, dita lei apenas foi regulamentada em 2011, por meio do Decreto 7.508.

\subsection{Princípios do direito à saúde}

A Constituição Federal consagra o direito à saúde como direito público subjetivo, a teor do artigo 196, que garante a saúde como direito de todos bem como as políticas sociais e o acesso universal e igualitário de ações para sua promoção e, como tal, direito fundamental.

Possuindo caráter de proteção fundamental, é importante o enfrentamento dos princípios garantidores do direito à saúde, os quais a seguir se discorre, tanto no enfoque constitucional quanto com relação à Lei 8.080/90, dando especial atenção aos princípios da dignidade da pessoa humana, do mínimo existencial e da reserva do possível, da universalidade e igualdade, da precaução e da prevenção.

\subsubsection{Princípio constitucional da dignnidade da pessoa humana - direito fundamental à saúde}

Ainda para SARLET, a dignidade da pessoa humana possui funções defensivas e assistenciais. A função defensiva refere-se a uma natureza com cunho de limitar a atuação estatal. Já a função assistencial se refere à atuação do Estado no sentido de promover políticas públicas para o aprimoramento do indivíduo. Neste sentido, refere que 
"qualidade intrínseca e distintiva reconhecida em cada ser humano que o faz merecedor do mesmo respeito e consideração por parte do Estado e da comunidade, implicando, neste sentido, um complexo de direitos e deveres fundamentais que assegurem a pessoa tanto contra todo e qualquer ato de cunho degradante e desumano, como venham a lhe garantir as condições existenciais mínimas para uma vida saudável" (SARLET, 2011, p.73).

No campo administrativo, verifica-se este princípio também como indicador de atividade estatal, vez que através dele se garantirá e promoverão políticas públicas relativamente ao direito fundamental à saúde, cujo Sistema Único de Saúde (SUS) é fonte desta garantia.

Conforme enuncia TESLLER, (2011, p.10) :

\begin{abstract}
A fundamentalidade material encontra-se na relevância da saúde, como bem tutelado, por ser diretamente relacionado a direitos maiores, como o direito à vida e à dignidade humana. Encerra em si um direito do qual deflui um dever fundamental, com diz expressamente o artigo 196: "A saúde é dever do Estado". Daí se pode afirmar que o direito à saúde depende de procedimentos, suportes, estrutura, organização para que possa ser efetivado, necessitando ademais de normas organizadoras sobre os modos e a possibilidade de exercer a sua fruição.
\end{abstract}

No contexto brasileiro, a dignidade da pessoa humana encontra fundamento no artigo $1^{\text {ol }}$ da Constituição Federal, e, na Declaração Universal dos Direitos Humanos, também no artigo $1^{\circ}{ }^{2}$ têm-se a dignidade da pessoa como fundamento essencial à condição humana, destacando-se a ainda sobre a igualdade e liberdade. Há evidente preocupação em demonstrar a importância deste princípio, já que se encontra consagrado desde o artigo primeiro de muitas das constituições ou declarações mundiais.

O princípio da dignidade da pessoa humana foi elevado como fundamento do Estado Democrático de Direito brasileiro, e, assim, necessariamente deverá integrar a interpretação dada aos demais dispositivos legais. No dizer de FIGUEIREDO (2007, p.53), a dignidade da pessoa humana constitui elemento pré-jurídico, razão pela qual é tido tal instituto como qualidade intrínseca, irrenunciável e inalienável da personalidade de todo o ser humano, estando ligada à sua proteção.

\footnotetext{
1 Artigo $1^{\circ}$ : A República Federativa do Brasil, formada pela união indissolúvel dos Estados e Municípios e do

Distrito Federal, constitui-se em Estado Democrático de Direito e tem como fundamentos: I - a soberania;

II - a cidadania

III - a dignidade da pessoa humana;

IV - os valores sociais do trabalho e da livre iniciativa; V - o

pluralismo político.

Parágrafo único. Todo o poder emana do povo, que o exerce por meio de representantes eleitos ou diretamente, nos termos desta Constituição. (Constituição Federal Brasileira);

2 Artigo $1^{\circ}$ Todos os seres humanos nascem livres e iguais em dignidade e em direitos. Dotados de razão e de consciência, devem agir uns para com os outros em espírito de fraternidade (Declaração Universal dos Direitos Humanos).
} 
Contudo, é de se reconhecer que existem limitações financeiro-econômicas relativamente aos cofres públicos, que obstaculizam a concretização deste princípio e dos direitos sociais propriamente ditos, do que decorre a análise seguinte que diz com o princípio do mínimo existencial da reserva do possível.

\subsubsection{Princípio constitucional do mínimo existencial e da reserva do possível}

O artigo $6^{\circ}$ da Constituição Federal de 1988 estabeleceu uma serie de direitos sociais, fundado nos direitos fundamentais. O mínimo existencial, surgido na Alemanha nos idos de 1950, consiste em um determinado grupo de direitos que são necessários à existência e manutenção da vida digna.

Já a reserva do possível (reserva do financeiramente possível) surgiu na Alemanha de 1972, quando, diante do aumento populacional após a Segunda Guerra, muitos jovens tentavam estudar nas universidades e não obtinham número suficiente de vagas, já que não se tinha estrutura suficiente. Em intervenção, o Tribunal Constitucional Federal alemão reconheceu o direito dos jovens ao estudo, contudo, reconheceu a impossibilidade material de disponibilização de vagas na universidade, ainda que o Estado alemão tenha promovido investimentos neste sentido, mas que se mostraram insuficientes.

Em nosso sistema, e, no dizer de SARLET (2007, 305), consiste a reserva do financeiramente possível em limite jurídico e fático dos direitos fundamentais. Esta dimensão fática se refere à inexistência de recursos financeiros, bem como materiais, que poderiam inviabilizar a concretização de algum direito social. Já a dimensão jurídica, refere-se ao fato de existirem meios e recursos para promoção dos direitos sociais, mas estes não são realizados.

Também, para BRAUNER \& FURLAN (2013, p. 120) imprescindível na esfera da saúde, a observação da reserva do possível conjuntamente com a análise da garantia do mínimo existencial, observando os critérios e requisitos pertinentes à tomada de decisão, como a observância do binômio da razoabilidade da pretensão e a disponibilidade do Estado.

Mas neste sentido, não se poderá admitir que o Estado se tome do princípio da reserva do possível a efeito de eximir-se de suas obrigações relativas aos direitos sociais, em especial ao direito à saúde. 


\subsubsection{Princípio da universalidade e da igualdade}

Os principios da universalidade e da igualdade dispõem sobre a relação entre o sistema e seus usuários, razao pela qual nao deverá existir distinção entre ultimos, seja de caráter nacional ou financeiro, na medida em que poderá fazer uso do Sistema Único de Saúde SUS - o estrangeiro e, ainda, aquele que tiver condições de acesar a rede privada de saúde, mas na oportunidade nao queira fazer.

Este principio, da universalidade, vem regulado pelo disposto no artigo 196 da Constituição Federal, e neste sentido, garante que a saúde é direito de todos e dever do Estado, pelo que se deverá garantir, mediante políticas sociais e econômicas, os riscos à saúde.

A universalidade implica, portanto, na possibilidade de acesso igual a todos os serviços, do que se inclui o conceito e a noçao de cidadania para oportunizar o atendimento ou a concessao de medicamento a todos que necessitam sem que, como referido, indagar sobre a condicao social daquele que dele necessita.

E, com relação ao princípio da igualdade, TESLER (2011, p.06) assinala:

Os serviços de saúde devem ser prestados de maneira uniforme e indiferenciada a todos, sem privilégios ou preconceitos. O princípio foi estabelecido para sepultar a política de favores, ou a cultura do favor, ou a ideia de que quem não podia pagar seria tratado como indigente. Por outro lado, o princípio da igualdade não tolera distinção entre usuários pagantes e não pagantes. Era a chamada "diferença de classe", isto é, a separação de ambientes, o oferecimento de melhores acomodações e refeições aos que podiam pagar. Tudo isso desprestigia o princípio da igualdade e não contribui para a prestação de um serviço digno e eficiente para todos. Por outro lado, a igualdade deve ser compreendida dentro da universalidade. Todos estão incluídos e são iguais em consideração e direitos.

Desta forma, ditos princípios complementam-se e devem ser considerados, para fins de apreciação administrativa ou judicial, de forma conjunta, principalmente no que pertine ou poderia repercutir quanto à capacidade financeiro-econômica do assistido, do que não se tem qualquer tipo de restrição expressa ou implícita.

\subsubsection{Princípio da prevenção e da precaução}

O artigo 196 da Constituição Federal estabelece a necessidade de controle sanitário e epidemiológico, no sentido de promover a prevenção e a recuperação da saúde do indivíduo. E, no presente estudo, destacaremos, dentre outros princípios denominados sanitários, o da 
prevenção e precaução, que se encontram ainda descritos no artigo 198 e 200 da referida norma federal. Neste sentido, TESLLER (2011, p.17, idem):

O princípio da prevenção está diretamente ligado à antecipada previsão de acontecimentos negativos ou incerteza sobre consequências e acontecimentos. Já o princípio de precaução significa que se há de agir antecipadamente frente a uma dupla fonte, a incerteza que é a ausência de conhecimento científico e o próprio perigo conhecido. Não é só exortação à tomada de cautela, mas significa a necessidade de prática de ações, como, por exemplo, pesquisas ou até medidas extremas como barreiras alfandegárias ou a destruição de produtos diante de ameaça de danos sérios e irreversíveis. A prevenção está genericamente no art. $2^{\circ}$ da Lei $n^{\circ}$ 6.939/1981, não é estática, atualiza-se constantemente. Prestigia-se a precaução quando não se permite que o SUS propicie tratamento sem comprovação científica estabelecida. A obrigatoriedade de registro e aprovação de medicamentos pela Anvisa é outro exemplo de aplicação do princípio. A saúde é um campo em que o risco é onipresente. Há comportamentos e estilos de vida arriscados. Os procedimentos médicos e terapias envolvem riscos e efeitos colaterais. O princípio da precaução tem como objetivo preservar os benefícios do desenvolvimento científico, agindo antecipadamente no sentido de assegurar a saúde pública.

Desta forma, através da prevenção se oportuniza evitar a concretização de riscos de danos à saúde, já a precaução objetiva a atuação na esfera cientifica tendente a evitar também danos maiores que ainda não se tenha confirmado o risco através de promoções científicas, mas que, diante do caso concreto, poderão vir a ocorrer.

O princípio da prevenção, descrito no artigo 198, II da Constituição Federal, tenciona que a saúde pública prime pela promoção de atividades preventivas à população. Estas medidas incluem tanto atividades no sentido de evitar a ocorrência de doenças, por meio do desenvolvimento cientifico, quanto às de promoção de políticas públicas visando ao saneamento básico, à promoção de um meio ambiente equilibrado e ideal e a conscientização sobre o conceito de saúde individual.

Frise-se que o artigo 196 da Constituição Federal define que saúde, além da ausência de doenças, se materializa através da redução de riscos de enfermidades, com a respectiva promoção e recuperação. E, na intenção de seguir este cumprimento, a Lei n. 8.080/1990, em seu art. $6^{\circ}, I$, d, define que está no campo de atuação do SUS a assistência terapêutica integral, inclusive farmacêutica, fazendo com que o Brasil adotasse, por exemplo, estratégica de política de medicamentos da Organização Mundial de Saúde (OMS).

Ainda que, tanto por disposição constitucional, quanto de regra contida na lei 8.080/1990 se tenha por princípio a adoção e promoção de medidas preventivas e de precaução, no tocante a medicamentos, pesquisas científicas, diversificação do número de internações e de 
políticas sociais, a garantia do direito fundamental à saúde muitas vezes se mostra inviabilizada pelo Estado, que, embora invista no sentido da melhoria do alcance e do atendimento, não consegue suportar a demanda, razão pela qual verifica-se o surgimento e o aumento da chamada judicialização da saúde.

\section{PODER JUDICIÁRIO E O DIREITO À SAÚDE}

\subsection{Da Judicialização da Saúde- Esfera judicial}

O direito fundamental à vida protegido constitucionalmente pelo caput do art. $5^{\circ}$ da Constituição Federal Brasileira de 1988, faz com que dele decorram uma gama de direitos previstos no ordenamento, entre os quais se destaca o direito à saúde e o direito ao meio ambiente ecologicamente equilibrado. Todos possuem, ademais, intrínseca ligação com o princípio da dignidade da pessoa humana, visto que ser titular do direito à vida significa dizer possuir o direito de nascer (proteção da vida uterina), continuar vivo e viver dignamente, conforme mencionado supra.

Impende destacar que não obstante o direito social fundamental à saúde seja norma constitucional de aplicação imediata (como apregoa o art. $5^{\circ}, \S 1^{\circ}$ da Constituição Federal), é inegável que possui conteúdo programático, na medida em que sua concretização se dá por meio de prestações positivas por parte do Estado, as quais são realizáveis por políticas públicas específicas. Portanto, a decisão política sobre a organização pública da saúde é de responsabilidade imediata do Poder Executivo e Legislativo, mormente o primeiro, nas três esferas da federação: União, Estados e Municípios, como referido no capítulo anterior, ao se tratar da Lei 8.080/1990 e de seu Decreto Regulamentador (Decreto 7.508/2011). De qualquer forma, a conduta esperada por parte desses entes políticos é a efetiva alocação de recursos à área da saúde, sob pena de, em assim não o fazendo, ocasionar frustração às justas expectativas depositadas pela população. Por isso se aduziu no primeiro capítulo que o direito fundamental à saúde é dual (dupla dimensão), isto é, além de direito fundamental de todos é também um dever fundamental ao vincular o Poder Público à sua efetivação ${ }^{3}$.

\footnotetext{
3 Art. 196 da CF/88: A saúde é direito de todos e dever do Estado, garantido mediante políticas sociais e econômicas que visem à redução do risco de doença e de outros agravos e ao acesso universal e igualitário às ações e serviços para sua promoção, proteção e recuperação.
} 
Nesse passo, é justamente quando esse direito à saúde não é atendido que desponta a judicialização da saúde, vale dizer, quando os entes políticos não cumprem com a sua prestação ou o serviço prestado é ineficiente, o que faz gerar uma pretensão de satisfação do direito material por parte do Judiciário. Por outras palavras, pode-se dizer que é na omissão ou na má regulamentação da Constituição pelos governantes (Poder Legislativo e Executivo, cada um na sua esfera de atribuição), principalmente no que pertine aos direitos sociais fundamentais que demandam prestações positivas do Estado (direitos sociais à prestação- direito à saúde) que aflora a procura do cidadão pelo Poder Judiciário, na esperança de ver efetivados os direitos lá preconizados. Portanto, repita-se: decorre daquela omissão ou má regulamentação da Constituição que o fenômeno da judicialização da saúde encontra espaço (em razão da transferência das decisões do campo parlamentar e executivo para os Tribunais).

Impende registrar que, no Brasil, foram nos momentos de redemocratização que se observou um considerável incremento de demandas ajuizadas perante o Poder Judiciário (LOBATO, 2004, p. 28), na medida em que os cidadãos passaram a se sentir como verdadeiros protagonistas de suas vidas, buscando, assim, nas situações de violação a direitos subjetivos a efetivação dos direitos que lhes foram assegurados na Constituição Federal ${ }^{4}$. Nesse contexto se inserem as postulações no âmbito da saúde, visto que o cidadão, vendo frustrado seu direito à saúde, seja por não conseguir por parte do Estado os medicamentos necessários para fazer frente à moléstia que lhe acomete, seja por não obter tratamento e atendimento dignos, vem movimentando a máquina judiciária e exigindo deste Poder a concretização da promessa constitucional do direito fundamental à saúde.

De fato, como a cada direito/interesse tutelado há, no plano processual, uma tutela jurisdicional adequada, pode-se dizer que possui garantido pela Carta da República o direito de ação judicial para buscar a efetivação do direito à saúde, o qual se caracteriza como direito fundamental e está consagrado na Constituição Federal brasileira no artigo $5^{\circ}$, inciso XXXV, que preceitua: a lei não excluirá da apreciação do Poder Judiciário lesão ou ameaça a direito; e inciso LIV, ao afirmar que ninguém será privado da liberdade ou de seus bens sem o devido processo legal. Referidos dispositivos consagram o direito de invocar a atividade jurisdicional como direito público subjetivo que não possui restrição temática, sendo sede, pois, do princípio da inafastabilidade do controle jurisdicional. A propósito, GRINOVER (2007, p.13) refere que dito princípio indica ao mesmo tempo o monopólio estatal na distribuição da justiça (ex parte principis), como o amplo acesso de todos à referida justiça (ex parte populi). 
Abordando sobre judicialização de situações que deveriam ser resolvidas perante a esfera política (Poder Executivo e Legislativo), BARROSO (2008, p. 02) explica:

\begin{abstract}
Algumas questões de larga repercussão política ou social estão sendo decididas por órgãos do Poder Judiciário, e não pelas instâncias políticas tradicionais: o Congresso Nacional e o Poder Executivo em cujo âmbito se encontram o Presidente da República, seus ministérios e a administração pública em geral. Como intuitivo, a judicialização envolve uma transferência de poder para juízes e tribunais, com alterações significativas na linguagem, na argumentação e no modo de participação da sociedade.
\end{abstract}

Destaque-se, ademais, que com o advento do Estado Constitucional ${ }^{5}$ o Poder Judiciário assumiu papel de relevo na vida política do Estado, haja vista que, como intérprete da Constituição, extrai dela a sua vontade (efetuando a jurisdição constitucional- controles de constitucionalidade difuso e abstrato), e a concretiza, aplicando diretamente os preceitos constitucionais sempre que isso possa ser feito, o que maximiza a ideia de cidadania. Nesse sentido, LOBATO (2004, p.27/28):

\begin{abstract}
Assim sendo, a cidadania brasileira, pós-Constituição de 1988, volta os olhos para a atuação do Poder Judiciário- esse terceiro órgão de soberania do Estado, que tem a função de fazer cumprir as leis, notadamente a Constituição. Importante é ressaltar que o sistema judicial brasileiro admite que todo cidadão tenha acesso ao Poder Judiciário para a proteção de seus direitos fundamentais, através de ações constitucionais especiais de natureza individual, tais como Habeas Corpus, o Mandado de Segurança ou ainda as criadas pela Constituição de 1988, a ação de habeas Data e o Mandado de Injunção. A ação judicial poderá assumir uma dimensão coletiva ou transindividual através das Ações de Mandado de Segurança coletivo, a Ação Popular ou a Ação Civil Pública.
\end{abstract}

\footnotetext{
${ }^{4}$ Por corolário lógico, nas épocas de regimes de exceção, observou-se uma estagnação ou até diminuição do acesso à justiça (Lobato, 2004, pag. 28).

5 Esse Estado Constitucional na ordem jurídica brasileira se instaura de modo amplo e efetivo com a Constituição Federal de 1988.
} 
Não se nega aqui que a atribuição primária e principal para gerir e regulamentar as políticas públicas pertença aos Poderes: Executivo e Legislativo por serem os legítimos representantes da vontade popular (democracia representativa- voto da maioria). O que se quer dizer é que na sua inércia, e uma vez provocado o Poder Judiciário, este deve examinar as questões que lhe foram postas para apreciação e proferir decisão de mérito, não lhe sendo autorizado imiscuir-se sob a justificativa da não legitimação política. Ora, é justamente em razão da Constituição Federal, que colocou o Poder Judiciário como seu guardião, e desse novo estatuto dos direitos fundamentais, que é imprescindível sua atuação concretizadora e criadora do Direito, impondo-se, por outro lado, a superação do entendimento de Montesquieu sobre a separação dos poderes do Estado. Ademais, é também o princípio da inafastabilidade da jurisdição que obriga o posicionamento do Judiciário, repita-se, em qualquer temática, no que se insere a seara da judicialização da política da saúde (política pública) e não apenas nas questões jurisdicionais. A propósito, destaca-se a contribuição doutrinária de BARBOZA e KOZICKI, (2012, p. 61):

É possível afirmar que a própria idéia de constitucionalismo e de previsão de questões políticas na Constituição permitiram que o Judiciário acabasse enfrentando qualquer questão política como sendo uma questão constitucional.(...) É possível afirmar que há um consenso no sentido de que a assunção de novos papéis pelo Judiciário, incluindo as decisões de questões políticas, morais, religiosas, centrais, tanto por parte da sociedade, quanto por parte dos próprios atores políticos, vem sendo aceita pela sociedade, uma vez que os próprios atores políticos vêem o Judiciário como um fórum apropriado para enfrentar essas questões.

Note-se que essa atuação do Judiciário coopera para reafirmação da harmonia e independência dos poderes, visto que o acesso à jurisdição é um dos principais recursos disponíveis para que o cidadão possa fazer valer seus direitos. Nesse contexto, igualmente com supedâneo no princípio da inafastabilidade da jurisdição que se defende a não aplicação da doutrina da auto-restrição judicial para as questões políticas (segundo a qual a revisão judicial importaria em afronta a vontade da maioria representada pelo parlamento, razão por que o Judiciário deveria eximir-se ao exame de questões políticas). Isso porque mesmo nas questões em que até se poderia cogitar de uma certa resistência por parte do Poder Judiciário ao exame do mérito do ato administrativo vem se observando uma atenuação desse rigorismo, diante de inúmeras decisões judiciais que autorizam o exame da sua legalidade, moralidade, validade, do que se destaca o precedente do STJ no RESP 493.811, relatoria da Min. Eliana Calmon, DJ 15.03.2004, quando expressamente referiu a possibilidade de controle pelo Poder Judiciário das razões de conveniência e oportunidade do administrador. 
Logo, o Poder Judiciário por meio do princípio da inafastabilidade da jurisdição decorrente do Estado Democrático de Direito deve não só interpretar a Constituição, mas, principalmente, como já referido, concretizá-la quando verificar inércia ou má gestão por parte dos Poderes: Legislativo e Executivo na execução das políticas públicas, em especial na concretização dos direitos fundamentais sociais (de cunho prestacional - positivos); não podendo as alegações de 'reserva do possível' (possibilidade de recursos e capacidade de dispor por parte do destinatário da norma) servir de obstáculo, haja vista o novo papel conferido ao judiciário como concretizador de direitos fundamentais, na promoção do processo democrático na construção de uma sociedade livre, justa e solidária.

Em artigo intitulado Direito à saúde, universalidade, integralidade e políticas públicas: princípios e requisitos em demandas judiciais por medicamentos, RIOS (2009, p. $02^{6}$ ) é enfático:

O direito à saúde também tem eficácia direta e imediata em face do Poder Judiciário que, diante das políticas públicas definidas e implementadas, tem o dever de garantir aos cidadãos os direitos subjetivos e em toda a sua extensão ali previstos. Essa eficácia imediata e direta do direito fundamental à saúde vai além, para o Poder Judiciário: diante de uma política pública definida legislativamente e bem executada pela Administração, ele pode ser chamado a definir se o conteúdo jurídico do direito à saúde alcança alguma outra prestação positiva, vale dizer, aferir a existência de direito decorrente diretamente da Constituição (direito originário à prestação de saúde) a alguma prestação de saúde, observadas as condições jurídicas e fáticas pertinentes. Isso é o que ocorre na maioria das ações, pleiteando o fornecimento de medicamentos: um provimento judicial que afirme a eficácia originária do direito à saúde a fim de obrigar a Administração a conceder medicação além daquilo que foi definido e previsto nas listas oficiais de medicamentos. Sustentar diversamente, negando qualquer possibilidade de eficácia originária do direito à saúde, implica sujeitar a força normativa da Constituição à legislação e à administração que, por suas próprias e exclusivas forças e decisões, acabariam por definir o conteúdo jurídico da norma de direito fundamental.

http://www.revistadoutrina.trf4.jus.br/index.htm?http://www.revistadoutrina.trf4.jus.br/artigos/edicao031/roger_r ios.html Acesso em 24/06/2015 
Com efeito, não é por outra razão, que na área do direito sanitário, vem se observando o crescente ajuizamento de demandas que propõem desde a obtenção de medicamentos até a realização de procedimentos em geral (como cirurgias), internações hospitalares e pedidos de explicações por parte dos médicos e hospitais sobre o prognóstico e diagnóstico do paciente, lastreado no direito à informação, que, além de previsto na Constituição Federal, tem assento no artigo $7^{\circ}$, incisos $\mathrm{Ve} \mathrm{VI}^{7}$ da Lei 8.080/90.

No síteo do Conselho Nacional de Justiça ${ }^{8}$ é possível verificar-se o número de ações judiciais com a temática de direito à saúde em tramitação até junho de 2014. No âmbito federal, observa-se que os cinco Tribunais Regionais Federais somavam 62.291 processos, sendo que o TRF4 é o que mais possui esse tipo de demanda, perfazendo o total de 35.587 (24.229 no primeiro grau e 11.058 no segundo grau). Por sua vez, no âmbito da justiça estadual, o Tribunal de Justiça do Rio Grande do Sul é o campeão ao processar 113.953 ações seguido do TJMG com 66.751 e TJRJ 46.883.

Neste contexto, convém historiar como as Cortes Superiores (STJ e STF) se posicionaram no decorrer do tempo a respeito da matéria. Frise-se que se escolheu referidos tribunais, porque são as responsáveis por alinhavar o entendimento das instâncias inferiores.

Pois bem, num primeiro momento o STJ entendia que ao Poder Judiciário não era possível influir no orçamento do Poder Executivo para, em detrimento do todo, beneficiar um direito subjetivo indivídual. Além disso, reconhecia a norma constitucional que prevê o direito à saúde como norma meramente programática. Nesse sentido, o precedente de relatoria do Min. Demócrito Reinaldo (DJU 17.06.96):

CONSTITUCIONAL. ADMINISTRATIVO. MANDADO DE SEGURANÇA. DIREITO LÍQUIDO E CERTO. INEXISTÊNCIA. Direito líquido e certo, para efeito de concessão de segurança, é aquele reconhecível de plano e decorrente de lei expressa ou de preceito constitucional, que atribua ao impetrante um direito subjetivo próprio. Normas constitucionais meramente programáticas - ad exemplum, o direito à saúde - protegem um interesse geral, todavia, não conferem, aos beneficiários desse interesse o poder de exigir sua satisfação - pela via do mandamus - uma vez que não delimitado o seu objeto, nem fixada a sua extensão, antes que o legislador exerça o múnus de completá-las através da legislação integrativa. Essas normas (arts. 195, 196, 204 e 227 da Constituição Federal de 1988) são de eficácia limitada, ou, em outras palavras, não têm força suficiente para desenvolver-se integralmente, 'ou não dispõem de

\footnotetext{
${ }^{7}$ Lei 8.080/90: Art. $7^{\circ}$, inciso V - direito à informação, às pessoas assistidas, sobre sua saúde; VI - divulgação de informações quanto ao potencial dos serviços de saúde e a sua utilização pelo usuário.

8 http://www.cnj.jus.br/images/programas/forumdasaude/demandasnostribunais.forumSaude.pdf Acesso em 24/06/2015
} 
eficácia plena', pois dependem, para ter incidência sobre os interesses tutelados, de legislação complementar. Na regra jurídico-constitucional que dispõe que 'todos têm direitos e o Estado o dever' - dever de saúde - como afiançam os constitucionalistas, na realidade todos não têm direito, porque a relação jurídica entre o cidadão e o Estado devedor não se fundamenta em vinculum juris gerador de obrigações, pelo que falta ao cidadão o direito subjetivo público, oponível ao Estado, de exigir em Juízo, as prestações prometidas a que o Estado se obriga por proposição ineficaz dos constituintes. No sistema jurídico pátrio, a nenhum órgão ou autoridade é permitido realizar despesas sem a devida previsão orçamentária, sob pena de incorrer no desvio de verbas.Recurso a que se nega provimento. Recurso em Mandado de Segurança n. 6.564/RS (95.0068782-8). - original sem grifo

Entretanto, por meio do voto de Relatoria do Ministro Celso de Mello, o Supremo

Tribunal Federal exarou novas luzes sobre a temática e expressamente enfatizou o dever do Poder Judiciário exprimir da Constituição Federal o direito à saúde e concretizá-lo. A propósito, o RE 271286 AgR/RS - AG.REG no Recurso Extraordinário, relatoria do Ministro Celso de Mello (Julgamento: 12/09/2000; Órgão Julgador: Segunda Turma; Publicação ACÓRDÃO ELETRÔNICO DJ 24-11-2000 PP-00101EMENT VOL-02013-07 PP-01409),

cuja ementa segue:

PACIENTE COM HIV/AIDS - PESSOA DESTITUIIDA DE RECURSOS FINANCEIROS - DIREITO À VIDA E À SAÚDE - FORNECIMENTO GRATUITO DE MEDICAMENTOS - DEVER CONSTITUCIONAL DO PODER PÚBLICO (CF, ARTS. 5º, CAPUT, E 196) - PRECEDENTES (STF) - RECURSO DE AGRAVO IMPROVIDO. O DIREITO À SAÚDE REPRESENTA CONSEQÜÊNCIA CONSTITUCIONAL INDISSOCIÁVEL DO DIREITO À VIDA. - O direito público subjetivo à saúde representa prerrogativa jurídica indisponível assegurada à generalidade das pessoas pela própria Constituição da República (art. 196). Traduz bem jurídico constitucionalmente tutelado, por cuja integridade deve velar, de maneira responsável, o Poder Público, a quem incumbe formular - e implementar - políticas sociais e econômicas idôneas que visem a garantir, aos cidadãos, inclusive àqueles portadores do vírus HIV, o acesso universal e igualitário à assistência farmacêutica e médicohospitalar. - $\mathrm{O}$ direito à saúde - além de qualificar-se como direito fundamental que assiste a todas as pessoas - representa consequiência constitucional indissociável do direito à vida. O Poder Público, qualquer que seja a esfera institucional de sua atuação no plano da organização federativa brasileira, não pode mostrar-se indiferente ao problema da saúde da população, sob pena de incidir, ainda que por censurável omissão, em grave comportamento inconstitucional. A INTERPRETAÇÃO DA NORMA PROGRAMÁTICA NÃO PODE TRANSFORMÁ- LA EM PROMESSA CONSTITUCIONAL INCONSEQÜENTE. - O caráter programático da regra inscrita no art. 196 da Carta Política - que tem por destinatários todos os entes políticos que compõem, no plano institucional, a organização federativa do Estado brasileiro - não pode converter-se em promessa constitucional inconseqüente, sob pena de o Poder Público, fraudando justas expectativas nele depositadas pela coletividade, substituir, 
de maneira ilegítima, o cumprimento de seu impostergável dever, por um gesto irresponsável de infidelidade governamental ao que determina a própria Lei Fundamental do Estado. DISTRIBUIÇÃO GRATUITA DE MEDICAMENTOS A PESSOAS CARENTES. - O reconhecimento judicial da validade jurídica de programas de distribuição gratuita de medicamentos a pessoas carentes, inclusive àquelas portadoras do vírus HIV/AIDS, dá efetividade a preceitos fundamentais da Constituição da República (arts.

$5^{\circ}$, caput, e 196) e representa, na concreção do seu alcance, um gesto reverente e solidário de apreço à vida e à saúde das pessoas, especialmente daquelas que nada têm e nada possuem, a não ser a consciência de sua própria humanidade e de sua essencial dignidade. Precedentes do STF. (grifou-se)

Essa é, pois, a posição defendida no presente trabalho, no sentido de que o Poder Judiciário, uma vez verificada a omissão do Poder Público, deve, quando instado, atuar como construtor do direito e conceder a prestação de saúde reclamada.

\subsection{Das Políticas Públicas para a saúde pelo Poder Judicário- esfera administrativa.}

O número elevado de processos judiciais visando ações relativas à concretização do direito à saúde foi o mote para que a Corte Constitucional designasse uma Audiência Pública, para discutir a matéria e cujos resultados seriam levados em consideração nas suas futuras decisões. Assim, foi designada a Audiência Pública nº 4, pelo então Presidente do STF, Ministro Gilmar Ferreira Mendes, a qual aconteceu entre os dias 27, 28 e 29 de abril, e 4, 6 e

7 de maio de 2009. Naquela oportunidade, foram ouvidos 50 (cinquenta) especialistas, entre advogados, defensores públicos, promotores e procuradores de justiça, magistrados, professores, médicos, técnicos de saúde, gestores e usuários do sistema único de saúde. ${ }^{9}$

Essa iniciativa inédita do Supremo Tribunal na Audiência Pública nº 04 abriu caminhos para a adoção de uma política pública judiciária para a saúde executada pelo Conselho Nacional de Justiça, ${ }^{10}$ a fim de dar contornos e monitoramento às demandas de saúde. Assim, o CNJ constituiu um grupo de trabalho por meio da Portaria n. 650, de 20 de novembro de 2009, que culminou na aprovação da Recomendação n. 31, de 30 de março de $2010^{11}$, a qual versa sobre diretrizes aos magistrados quanto às demandas judiciais que

\footnotetext{
9 Informações colhidas no portal:

http://www.stf.jus.br/portal/cms/verTexto.asp?servico=processoAudienciaPublicaSaude Acesso em 02/06/2015.

10 o Conselho Nacional de Justiça (CNJ), criado em 31 de dezembro de 2004 e instalado em 14 de julho de

2005, foi instituído em razão do artigo 103-B da CF/88. O CNJ possuir por missão institucional a tomada de ações de planejamento, coordenação e controle administrativo, visando aperfeiçoar o serviço público de prestação da Justiça.

11 A Recomendação n⿳o 31/2010 afirma a relevância da matéria para a garantia de uma vida digna à população brasileira. Nesse aspecto, vincula-se ao princípio da dignidade humana e prestigiamento do constitucionalismo. Considera as dificuldades enfrentadas pelos magistrados, especialmente as carências sobre informações clínicas relativas aos demandantes. Pondera que os medicamentos e outros insumos, para serem utilizados no Brasil, necessitam de prévia aprovação pela Anvisa, na forma do artigo 12 da Lei ${ }^{\circ} 6.360 / 1973$ c/c Lei $n^{\circ} 9.782 / 1999$.
} 
envolvem a assistência à saúde. Por sua vez, em 06 de abril de 2010, o CNJ publicou a Resolução $n^{\circ} 107$, que instituiu o Fórum Nacional do Judiciário, o qual é coordenado por um Comitê Executivo Nacional (Portaria n. 40 de 25 de março de 2014) e constituído por Comitês Estaduais. Ademais, por meio da Resolução 107 do CNJ, foi criado um sistema eletrônico de acompanhamento das ações judiciais que envolvem a assistência à saúde, chamado Sistema Resolução 107. Na atualidade, o Fórum da Saúde ampliou sua área de atuação para incluir a saúde suplementar e as ações resultantes das relações de consumo. ${ }^{12}$

Exemplo concreto das orientações aos juízes em matéria de saúde promovido pela gestão administrativa do CNJ no Fórum Nacional da Saúde são os Enunciados decorrentes da Primeira e Segunda Jornada de Direito da Saúde promovido por referido Conselho. A primeira jornada, realizada em 15 de maio de 2014, na capital de São Paulo-SP, aprovou 45 enunciados $^{13}$, e a segunda, ocorrida nos dias 18 e 19 de maio de 2015, igualmente em SP, aprovou mais 22 novos enunciados ${ }^{14}$. Os Enunciados versam sobre saúde pública, suplementar e biodireito ${ }^{15}$. Dentre os de saúde pública, destacam-se os que seguem:

Reafirma a importância da oitiva dos gestores públicos, bem como sobre a necessidade de assegurar a sustentabilidade e o gerenciamento do SUS. (TESSLER, 2011, P. 11)

12 Informações extraídas do siteo http://www.cnj.jus.br/busca?termo=forum+nacional+saude Acesso em $25 / 06 / 2015$

3

http://www.cnj.jus.br/images/ENUNCIADOS_APROVADOS_NA_JORNADA_DE_DIREITO_DA_SAUDE_

\%20PLENRIA_15_5_14_r.pdf Acesso em 25 de junho de 2015.

14 http://www.cnj.jus.br/files/conteudo/destaques/arquivo/2015/05/96b5b10aec7e5954fcc1978473e4cd80.pdf

Acesso em 25 de junho 2015.

15 ENUNCIADOS BIODIREITO:

ENUNCIADO N. ${ }^{\circ} 37$

As diretivas ou declarações antecipadas de vontade, que especificam os tratamentos médicos que o declarante deseja ou não se submeter quando incapacitado de expressar-se autonomamente, devem ser feitas preferencialmente por escrito, por instrumento particular, com duas testemunhas, ou público, sem prejuízo de outras formas inequívocas de manifestação admitidas em direito. ENUNCIADO N. ${ }^{\circ} 38$ :

Nas pesquisas envolvendo seres humanos deve ser assegurada a proteção dos direitos fundamentais dos participantes da pesquisa, além da avaliação da necessidade, utilidade e proporcionalidade do procedimento, com o máximo de benefícios e mínimo de danos e riscos.

ENUNCIADO N. ${ }^{\circ} 39$

O estado de filiação não decorre apenas do vínculo genético, incluindo a reprodução assistida com material genético de terceiro, derivando da manifestação inequívoca de vontade da parte.

ENUNCIADO N. ${ }^{\circ} 40$

É admissível, no registro de nascimento de indivíduo gerado por reprodução assistida, a inclusão do nome de duas pessoas do mesmo sexo, como pais.

ENUNCIADO N..$^{\circ} 4$

$\mathrm{O}$ estabelecimento da idade máxima de 50 anos, para que mulheres possam submeter-se ao tratamento e à gestação por reprodução assistida, afronta o direito constitucional à liberdade de planejamento familiar. ENUNCIADO N. ${ }^{\circ} 42$

Quando comprovado o desejo de viver e ser aceito enquanto pessoa do sexo oposto, resultando numa incongruência entre a identidade determinada pela anatomia de nascimento e a identidade sentida, a cirurgia de transgenitalização é dispensável para a retificação de nome no registro civil.

ENUNCIADO N. ${ }^{\circ} 43$ 
03: Recomenda-se ao autor da ação, a busca preliminar sobre disponibilidade do atendimento, evitando-se a judicialização desnecessária.

06: A determinação judicial de fornecimento de fármacos deve evitar os medicamentos ainda não registrados na Anvisa, ou em fase experimental, ressalvadas as exceções expressamente previstas em lei. ${ }^{16}$

07: Sem prejuízo dos casos urgentes, visando respeitar as competências do SUS definidas em lei para o atendimento universal às demandas do setor de saúde, recomenda-se nas demandas contra o poder público nas quais se pleiteia dispensação de medicamentos ou tratamentos para o câncer, caso atendidos por médicos particulares, que os juízes determinem a inclusão no cadastro, o acompanhamento e o tratamento junto a uma unidade CACON/UNACON.

08: Nas condenações judiciais sobre ações e serviços de saúde devem ser observadas, quando possível, as regras administrativas de repartição de competência entre os gestores.

15 :As prescrições médicas devem consignar o tratamento necessário ou o medicamento indicado, contendo a sua Denominação Comum Brasileira (DCB) ou, na sua falta, a Denominação Comum Internacional (DCI), o seu princípio ativo, seguido, quando pertinente, do nome de referência da substância, posologia, modo de administração e período de tempo do tratamento e, em caso de prescrição diversa daquela expressamente informada por seu fabricante, a justificativa técnica.

16 :Nas demandas que visam acesso a ações e serviços da saúde diferenciada daquelas oferecidas pelo Sistema Único de Saúde, o autor deve apresentar prova da evidência científica, a inexistência, inefetividade ou impropriedade dos procedimentos ou medicamentos constantes dos protocolos clínicos do SUS.

50 - Saúde Pública - Salvo prova da evidência científica e necessidade preemente, não devem ser deferidas medidas judiciais de acesso amedicamentos e materiais não registrados pela ANVISA ou para uso off label. Não podem ser deferidas medidas judiciais que assegurem o acesso a produtos ou procedimentos experimentais.

51 - Saúde Pública - Nos processos judiciais, a caracterização da urgência/emergência requer relatório médico circunstanciado, com expressa menção do quadro clínico de risco imediato.

52 - Saúde Pública - Nas ações reiteradas na mesma Comarca que apresentem pedidos de medicamentos, produtos ou procedimentos já previstos nas listas oficiais, como medida de eficácia da atuação jurisdicional, é pertinente o magistrado dar ciência dos fatos aos Conselhos Municipal e Estadual de Saúde.

58 - Saúde Pública - Quando houver prescrição de medicamento, produto, órteses, próteses ou procedimentos que não constem em lista (RENAME /RENASES) ou protocolo do SUS, recomenda-se a notificação judicial do médico prescritor, para que preste esclarecimentos sobre a pertinência e

É possível a retificação do sexo jurídico sem a realização da cirurgia de transgenitalização.

ENUNCIADO N. ${ }^{\circ} 44$

O absolutamente incapaz em risco de morte pode ser obrigado a submeter-se a tratamento médico contra à vontade do seu representante.

ENUNCIADO N. ${ }^{\circ} 45$

Nas hipóteses de reprodução humana assistida, nos casos de gestação de substituição, a determinação do vínculo de filiação deve contemplar os autores do projeto parental, que promoveram o procedimento.

ENUNCIADO $\mathrm{N}^{\circ}$ 68: Os direitos reprodutivos correspondem ao conjunto de direitos básicos relacionados com o livre exercício da sexualidade e da reprodução humana.

16 Consagra o princípio da precaução em matéria de direito sanitário. 
necessidade da prescrição, bem como para firmar declaração de eventual conflito de interesse.

59 - Saúde Pública - As demandas por procedimentos, medicamentos, próteses, órteses e materiais especiais, fora das listas oficiais, devem estar fundadas na Medicina Baseada em Evidências.

60 - Saúde Pública - A responsabilidade solidária dos entes da Federação não impede que o Juízo, ao deferir medida liminar ou definitiva, direcione inicialmente o seu cumprimento a um determinado ente, conforme as regras administrativas de repartição de competências, sem prejuízo do redirecionamento em caso de descumprimento ${ }^{17}$.

Como visto, o CNJ está promovendo verdadeira política pública judicial na área da saúde, ao servir de orientador e balizador das decisões judiciais, na medida em que, como muito bem apregoa TESSLER (2011, P. 13):

(...). Na sua missão institucional está a oferecer aproximação com os atores institucionais na área da saúde. Constrói gradativamente "organização e procedimentos", que são um dever imposto às instituições públicas da área, no sentido de oferecer e tornar possível uma decisão segura pelo Juiz e a fruição por todos do direito assegurado. No contato democrático com a sociedade, procurou recolher as múltiplas perspectivas em torno do assunto. $\mathrm{Na}$ área pública, procurou fazer com que o Estado tome consciência da relevância da matéria, todas iniciativas tendentes a resolver a excessiva judicialização. Construiu políticas públicas judiciárias, organização e procedimentos para dar plenas condições para o melhor desempenho da jurisdição. Pode-se afirmar que as recomendações vertidas na Recomendação $n^{\circ}$ 31/2010 do Conselho Nacional de Justiça constituem política pública judicial para melhor composição dos litígios e maior efetividade do direito constitucional à saúde.

A efetivação destas políticas de aproximação entre saúde e o Judiciário concretiza a realização do princípio da dignidade da pessoa humana, já que o a jurisdição encontra fluidez quando também concretiza esta missão institucional.

\section{QUESTÕES DIVERSAS NOS PROCESSOS JUDICIAIS DE SAÚDE}

\subsection{Responsabilidade Solidária dos entes federativos}

Consoante visto no primeiro capítulo, na esteira do artigo 198 da CF, são responsáveis pela gestão do SUS, de modo solidário, a União, os Estados, Distrito Federal e os Municípios. As atribuições específicas de cada ente federativo, por sua vez, encontram-se preconizadas de modo detalhado na Lei $12.401 / 2011$, a qual alterou a Lei 8.080/1990, e no Decreto 7.508/2011.

\footnotetext{
${ }^{17}$ Ratifica o Enunciado 08.
} 
Note-se que a distinção das competências entre os entes federativos deve ser entendida como modo de organização e prestação do serviço público de saúde, de modo a atender, ao fim e ao cabo, o princípio da eficiência administrativa.

Pois bem, não obstante a previsão constitucional e legal a indicar uma distribuição das competências, prevalece o entendimento jurisprudencial no sentido de que a responsabilidade é solidária, logo, não há litisconsórcio passivo necessário, litispendência, ou conexão entre demandas propostas pelo mesmo autor perante a justiça estadual ou federal, devendo ser examinado apenas o princípio da demanda, no sentido de que cabe ao demandante escolher contra quem quer litigar. Nessa linha, seguem alguns exemplos de decisões do STJ e TRF $4{ }^{a}$ Região, não negritadas no original:

ADMINISTRATIVO. AGRAVO REGIMENTAL. FORNECIMENTO DE REMÉDIO. DIREITO À VIDA E À SAÚDE. RESPONSABILIDADE SOLIDÁRIA DOS ENTES FEDERATIVOS.

1. (...) 3. A jurisprudência do Superior Tribunal de Justiça consolidou-se no sentido de que 'o funcionamento do Sistema Único de Saúde (SUS) é de responsabilidade solidária da União, Estados-membros e Municípios, de modo que qualquer dessas entidades têm legitimidade ad causam para figurar no pólo passivo de demanda que objetiva a garantia do acesso à medicação para pessoas desprovidas de recursos financeiros' (REsp 771.537/RJ, Rel. Min. Eliana Calmon, Segunda Turma, DJ 3.10.2005). 4. Agravo regimental não provido. (AgRg no Ag 907.820/SC, Rel. Ministro MAURO CAMPBELL MARQUES, SEGUNDA TURMA, julgado em 15/04/2010, DJe 05/05/2010)

AGRAVO REGIMENTAL EM RECURSO ESPECIAL. PROCESSUAL CIVIL. ADMINISTRATIVO. AGRAVO DE INSTRUMENTO. RECURSO ESPECIAL. TRATAMENTO MÉDICO NO EXTERIOR. ARTIGO 196 DA CF/88. DIREITO À VIDA E À SAÚDE. DEVER DA UNIÃO. LEGITIMIDADE PASSIVA. [...] 4. A União, o Estado, o Distrito Federal e o Município são partes legítimas para figurar no pólo passivo nas demandas cuja pretensão é o fornecimento de medicamentos imprescindíveis à saúde de pessoa carente, podendo a ação ser proposta em face de quaisquer deles. Precedentes: REsp 878080 / SC; Segunda Turma; DJ 20.11.2006 p. 296; REsp 772264 / RJ; Segunda Turma; DJ 09.05.2006 p. 207; REsp 656979 / RS, DJ 07.03.2005. [...] (STJ, AgRg no REsp 1028835/DF, Primeira Turma, Relator Ministro Luiz Fux, julgado em 02/12/2008, DJe 15/12/2008)

ADMINISTRATIVO E CONSTITUCIONAL. REALIZAÇÃO DE CIRURGIA. ENTES POLÍTICOS - RESPONSABILIDADE SOLIDÁRIA. DIREITO AO RECEBIMENTO - REQUISITOS. PERÍCIA DESNECESSIDADE NO CASO CONCRETO. 1. A União, EstadosMembros e Municípios têm legitimidade passiva e responsabilidade solidária nas causas que versam sobre realização de atos concernentes à manutenção ou melhora de saúde. 2. Desnecessária a realização de perícia quando as provas acostadas apresentam-se suficientes para o convencimento 
quanto à real necessidade de realização de cirurgia, mormente quando aquele que recomenda o procedimento é o próprio SUS. (TRF4, AC 2007.72.09.000171-1, Terceira Turma, Relatora Maria Lúcia Luz Leiria, D.E. 02/06/2010)

ADMINISTRATIVO. SAÚDE. INTERNAÇÃO EM UTI PEDIÁTRICA SEMI-INTENSIVA. LEGITIMIDADE PASSIVA. PRAZO. MULTA. 1. A União, Estados-Membros e Municípios têm legitimidade passiva e responsabilidade solidária nas causas que versam sobre serviços de saúde pública ou fornecimento de medicamentos. 2. A solidariedade não induz litisconsórcio passivo necessário, mas facultativo, cabendo à parte autora a escolha daquele contra quem deseja litigar, sem obrigatoriedade de inclusão dos demais. Se a parte escolhe litigar somente contra um ou dois dos entes federados, não há a obrigatoriedade de inclusão dos demais. 3. (...). (TRF4, AG 5017883-

32.2014.404.0000, Quarta Turma, Relator p/ Acórdão Luís Alberto D'azevedo Aurvalle, juntado aos autos em 25/09/2014)

A jurisprudência do Supremo Tribunal Federal segue a mesma linha acima consignada e foi reafirmada pelo Ministro Gilmar Mendes por ocasião da Suspensão de Tutela Antecipada $\mathrm{n}^{\circ} 175$, que consagrou a responsabilidade solidária entre Municípios, Estados, Distrito Federal e União ${ }^{18}$.

Destaque-se, contudo, que em sendo possível atribuir-se a obrigação pelo cumprimento da decisão judicial ao ente federativo que efetivamente seja o responsável por aquela política pública é recomendável que assim decida o magistrado, até porque reduz a ingerência na gestão administrativa do Estado e a execução tende a ser mais efetiva. Não foi por outra razão que o Fórum Nacional da Saúde, segundo visto no capítulo anterior, aprovou os Enunciados 08 e 60 já transcritos. No mesmo sentido GEBRAN E DRESCH $(2014,103)$ :

Havendo política pública que estabeleça obrigações a mais de um ente público, a decisão que determinar a prestação material deverá definir, na medida do possível, a quem cabe prestar diretamente a obrigação como responsável pelo custeio ou reembolso como previsto no art. 35, VII da Lei

8.080/90, em atenção na legislação do SUS e nos contratos organizativos.

\subsection{Diretrizes para uma adequada conformação do direito à saúde}

Importa referir, por fim, algumas medidas que devem ser observadas nas ações judiciais, para que se tenha uma efetiva conformação do direito à saúde. Nessa senda, RIOS (2009, p. 08) ensina que a concretização do direito à saúde pode sofrer restrições quando em colisão com outros direitos e bens constitucionais relevantes. Em suas palavras: 
Cumpre concretizar o direito ao fornecimento de medicamentos a partir de uma compreensão da Constituição e dos direitos fundamentais que tenha seu ponto de partida nos direitos à vida, à saúde, ao respeito à dignidade humana e à liberdade fática, opondo-lhes, quando for o caso e somente se necessário, as restrições trazidas por outros direitos e bens constitucionais. Esse procedimento, no âmbito da contemporânea teoria dos direitos fundamentais, pode ser denominado método hermenêutico constitucional contextual, para utilizar a expressão de Juan Carlos Gavara de Cara, pois parte da própria Constituição, da conexão e da inter-relação entre as diversas normas de direitos fundamentais.(...)Sem a pretensão de um rol exaustivo, para os fins deste estudo destacam-se, de um lado, o direito à vida, à saúde, o respeito à dignidade humana e à liberdade fática, em contraposição à competência orçamentária do legislador, ao princípio democrático, à reserva do possível e à eficiência da atividade administrativa.

Nesse passo, para que haja uma prestação jurisdicional adequada e suficiente, de modo a atender a direito subjetivo individual sem sacrificar os demais usuários do SUS, é fundamental que o magistrado verifique se efetivamente o medicamento ou o procedimento postulado realmente atende a uma melhora na qualidade de vida e saúde do paciente, não se traduzindo em mero conforto, e que, jamais, acabe por lhe prejudicar a saúde. Isso em nome do princípio bioético da beneficência, o qual é informador o direito à saúde.

De outro lado, a decisão judicial não pode importar em graves danos ao funcionamento do serviço público de saúde como um todo, porque tal agir importa em lesão ao direito à saúde dos demais membros da sociedade.

${ }^{18} \mathrm{Na}$ mesma decisão, há um reconhecimento de que a matéria deverá ser objeto de exame específico pela Suprema Corte no julgamento do RE 566.471 e na Proposta de Súmula vinculante em trâmite na Suprema Corte. 
É fundamental, outrossim, que o juiz determine a realização de perícia nos autos, a fim de averiguar a necessidade e adequação do medicamento/procedimento médico requerido. Ademais, a perícia deve considerar a existência de protocolos clínicos e terapêuticos, no âmbito do Ministério da Saúde, sobre a patologia investigada e o perito deve manifestar suas conclusões à luz da chamada "medicina das evidências"; além de assinar, tanto o perito judicial como o subscritor da prescrição, um termo de ausência de conflito de interesses, da qual se extraia a sua não vinculação a qualquer fabricante, fornecedor, entidade ou pessoa interessada no processo de produção e comercialização do medicamento/procedimento avaliado .

Veja-se, contudo, que será possível a não designação de perícia para se decidir sobre pedido de antecipação dos efeitos da tutela nas situações em que restar evidenciada a urgência da medida conjugada ao fato de o médico que assina a requisição do medicamento/procedimento ser conveniado ao Sistema Único de Saúde. De qualquer forma essa é uma situação excepcional.

Em finalizando, destaca-se que em razão dos princípios da universalidade de acesso aos serviços de saúde, da integralidade das ações e serviços preventivos e curativos de saúde e da igualdade da assistência à saúde, sem preconceito de qualquer espécie, o que evita a estigmatização do pobre, o serviço público de saúde é devido a todos os indivíduos que estejam em território nacional. Portanto, desinteressa as condições de renda do beneficiário, razão por que pode ocorrer que a parte autora não tenha gratuidade da justiça, por poder responder pelas despesas do processo, mas mesmo assim receba o medicamento via SUS. Entretanto, essa questão é polêmica, exigindo, alguns tribunais, que na ação judicial o requerente comprove a ausência de condições financeiras para suportar o tratamento via particular, sendo o deferimento da assistência judiciária gratuita um elemento reforçador da sua incapacidade financeira.

No sentido do texto, segue importante precedente do TRF $4^{\text {a }}$ Região (sem negrito no original):

AGRAVO DE INSTRUMENTO. PROCESSUAL CIVIL E DIREITO CONSTITUCIONAL. LEGITIMIDADE PASSIVA. DIREITO À SAÚDE. SISTEMA ÚNICO DA SAÚDE - SUS. EFICÁCIA IMEDIATA. PRESTAÇÃO POSITIVA DE FORNECIMENTO DE MEDICAÇÃO. FORÇA NORMATIVA DA CONSTITUIÇÃO. PROPORCIONALIDADE. 1. Mercê do disposto no art. $4^{\circ}$ da Lei $\mathrm{n}^{\circ} 8.080$, de 19 de setembro de 1990 , conjugado com o art. 196 da Lei Maior, é obrigação do Estado, no sentido genérico (União, Estados e Municípios) assegurar às pessoas desprovidas de recursos financeiros o acesso à medicação necessária. 2. O direito à saúde é direito fundamental, dotado de eficácia e aplicabilidade imediatas, apto a 
produzir direitos e deveres entre as partes, superada a noção de norma meramente programática, sob pena de esvaziamento da força normativa da Constituição. 3. A doutrina e a jurisprudência constitucionais contemporâneas admitem a eficácia direta da norma constitucional que assegura o direito à saúde, ao menos quando as prestações são de grande importância para seus titulares e inexiste risco de dano financeiro grave, o que inclui o direito à assistência médica vital, que prevalece, em princípio, inclusive quando ponderado em face de outros princípios e bens jurídicos. 4. O princípio de interpretação constitucional da concordância prática exige que se concretizem os direitos fundamentais emprestandolhes a maior eficácia possível e evitando restrições desnecessárias a outros princípios constitucionais, bem como a ofensa a direitos fundamentais de outros indivíduos e grupos. 5. O direito ao fornecimento de medicamentos deve considerar a competência orçamentária do legislador, a reserva do possível e a eficiência da atividade administrativa, sem perder de vista a relevância primordial da preservação do direito à vida e o direito à saúde. 6. Nesta atividade concretizadora e à luz dos princípios informadores do SUS (da universalidade, da integralidade e da gratuidade), deve-se atentar para que: a) eventual provimento judicial concessivo de medicamento acabe, involuntariamente, prejudicando a saúde do cidadão cujo direito se quer proteger, em contrariedade completa com o princípio bioético da beneficência, cujo conteúdo informa o direito à saúde; b) eventual concessão não cause danos e prejuízos relevantes para o funcionamento do serviço público de saúde, o que pode vir em detrimento do direito à saúde de outros cidadãos; c) não haja prevalência desproporcional do direito à saúde de um indivíduo sobre os princípios constitucionais da competência orçamentária do legislador e das atribuições administrativas do Poder Executivo, em contrariedade ao princípio da concordância prática na concorrência de direitos fundamentais. 7. Admite-se como prova suficiente para a antecipação da tutela judicial, antes mesmo de perícia exaustiva, manifestações médicas e informações que demonstrem a propriedade do tratamento demandado, a inexistência de alternativa aceitável no âmbito dos recursos disponibilizados no sistema público de saúde e a aprovação do medicamento ou tratamento pela ANVISA e/ou outros órgãos competentes. 8. Agravo desprovido, porquanto não trazidos elementos, sequer indiciários, a justificar o fornecimento da medicação. (Processo AG 200904000112309 AG - AGRAVO DE INSTRUMENTO Relator (a) NICOLAU KONKEL JÚNIOR TRF4 Órgão julgador: TERCEIRA TURMA D.E. 10/03/2010)

Referido precedente consolida a viabilidade no tocante a aplicação dos principios fundamentais que viabilizam o direito fundamental à saúde sopesado à ausência de prejuízo financeiro à administração (orçamento) ou a outros indivíduso, bem como como da beneficência relativamente ao tratamento necessário, em destaque. 


\section{CONCLUSÃO}

Pelo exposto, verifica-se que a Constituição Federal de 1988 traduz o direito à saúde como direito fundamental do cidadão, e, neste sentido, a garantia deste direito como modo de preservação da dignidade humana, será de relevância inclusive para o Poder Judiciário.

A efetivação da saúde pública deve ser concretizada não somente através de tratamentos imediatos, mas também de outros meios que visem ao desenvolvimento da saúde individual e coletivo da população. É de se destacar, contudo, que existem limitadores financeiros ao administrador da saúde pública, o qual muitas vezes confronta e sopesa ao direito à dignidade humana.

A fim de promover um equilíbrio entre dois princípios essenciais, então, importante será a verificação de investimentos em políticas administrativas de assistência à saúde. E, diante do elevado número de demandas que chegam também ao judiciário, aqui demonstradas e que tendem a aumentar, estas políticas também partirão de sua iniciativa, já que não somente através da análise do fato concreto atuará, mas também através de atividades educativas no sentido da promoção da prevenção deste direito.

Da narrativa apresentada, conformou-se que o Poder Judiciário encontra plena legitimidade para manifestar-se nas ações que envolvem a proteção do direito à saúde, uma vez que a saúde não se configura somente como direito, mas também como dever do Estado, e, em caso de lesão ou ameaça, por certo comporá o litígio ao determinar as medidas que entender cabíveis.

Neste sentido, em vista da inafastabilidade jurisdicional, decorrente do Estado democrático de direito, caberá ao Poder Judiciário concretizar o direito à saúde, no caso de inercia ou má gestão do Executivo, ainda que, por uma primeira posição do STJ aqui demonstrada, entendia-se que ao Poder Judiciário não seria possível influir no orçamento do Poder Executivo, em detrimento de um direito subjetivo individual, do que se teve renovação de entendimento no sentido de que caberá ao judiciário o dever de exprimir da Constituição Federal o direito à saúde e, concretizá-lo. 


\section{REFERÊNCIAS BIBLIOGRÁFICAS}

BARBOZA, Estefânia Maria de Queiroz; KOZICKI, Katya. "Judicialização da política e controle judicial de políticas públicas." Revista Direito GV. São Paulo, n. 8(1), p. 59-86, 2012.

BARROSO, Luis Roberto. "Judicialização, Ativismo e Legitimidade democrática". Revista eletrônica de direito do Estado, $\mathrm{n}^{\circ}$ 18- abril / maio / junho de 2009. Disponível em: $<$ http://www.direitodoestado.com/ revista/REDE-18-ABRIL-2009-

LUIS\%20BARROSO.pdf>. Acessado em: 15/05/2015.

BRAUNER, Maria Claudia Crespo; FURLAN, Karina Morgana. "O crescente processo de medicalização da vida: entre a judicialização da saúde e um novo modelo biomédico. " In Direitos humanos, saúde e medicina: uma perspectiva internacional. - Rio Grande, RS: Ed. Da FURG, 2013.

GEBRAN NETO, João Pedro, DRESCH, Renato Luiz. "A responsabilidade Solidária e subsidiária dos entes políticos nas ações e serviços de saúde". In REVISTA NUMERO 84 do TRF 4' Região. Porto Alegre, Ano 25, 2014, pag. 77-103.

GRINOVER, Ada Pellegrini. "Inafastabilidade do controle jurisdicional e uma nova modalidade de autotutela (parágrafos únicos dos art. 249 e 251 do Código Civil) ". Revista Brasileira de Direito Constitucional - RBDC n. 10 - jul. /dez. 2007, página 13 (http://www.esdc.com.br/RBDC/RBDC-10/RBDC-10-013-Ada_Pellegrini_Grinover.pdf) acesso em 24/06/2015

LOBATO, Anderson Orestes Cavalcante. "Os Direitos Humanos na Constituição brasileira: desafios da efetividade". In: Direitos Humanos e Violência: desafios da ciência e da prática. Organizado por Georges Maluschke e outros. Fortaleza: Fundação Konrad Adenauer, p. 19-32, 2004.

FIGUEIREDO, Mariana Filchtiner. Direito Fundamental à Saúde. Parâmetros para sua eficácia e efetividade. $1^{\mathrm{a}}$ ed. Porto Alegre. Livraria do Advogado, 2007.

MARQUES, Nadia Rejane Chagas. O direito à saúde no Brasil- entre a norma e o fato. Porto Alegre: Nuria Fabris Editora, 2012.

RIOS, Roger Raupp. "Direito à saúde, universalidade, integralidade e políticas públicas: princípios e requisitos em demandas judiciais por medicamentos" Revista de Doutrina do $\begin{array}{llll}\text { TRF4. } & \text { Publicado 28.08.2009. }\end{array}$ http://www.revistadoutrina.trf4.jus.br/index.htm?http://www.revistadoutrina.trf4.jus.br/arti gos/edicao031/roger_rios.html Acessado em 24/06/2015 
SARLET, Ingo Wolfgang. A eficácia dos direitos fundamentais. 8. ed. Porto Alegre. Livraria do Advogado, 2007.

Dignidade da Pessoa Humana e Direitos Fundamentais na Constituição Federal de 1988. 5. ed. Porto Alegre. Livraria do Advogado, 2007.

Dignidade da Pessoa Humana e Direitos Fundamentais na Constituição Federal de 1988. 9a. ed. Porto Alegre. Livraria do Advogado, 2011.

"As dimensões da dignidade da pessoa humana: uma compreensão jurídico-constitucional aberta e compatível com os desafios da biotecnologia”. Coordenado por Sarlet, Ingo Wolfgang e Leite, Salomão George. In: Direitos Fundamentais e Biotecnologia. São Paulo: Editora Método, p. [13-41], 2007.

TESSLER, Marga Inge Barth. "As recomendações do Conselho Nacional de Justiça em face das demandas judiciais envolvendo a assistência à saúde". Revista de Doutrina da $4^{\mathrm{a}}$ Região, Porto Alegre, n. 42, jun. 2011. Disponível em: http://www.revistadoutrina.trf4.jus.br/artigos/edicao042/marga_tessler.html Acesso em: 25 jun. 2015. 